\title{
The effects of non-pharmaceutical interventions on SARS-CoV-2 transmission in different socioeconomic populations in Kuwait: a modeling study
}

Fatima Khadadah ${ }^{1,2^{*}+} \mathbb{D}$, Abdullah A. Al-Shammari ${ }^{3,4^{*}+}$, Ahmad Alhashemi ${ }^{5}$, Dari Alhuwail ${ }^{4,6}$, Bader Al-Saif ${ }^{7,8}$, Saud N. Alzaid ${ }^{9}$, Barrak Alahmad ${ }^{10}$ and Isaac I. Bogoch ${ }^{1}$

\begin{abstract}
Background: Aggressive non-pharmaceutical interventions (NPIs) may reduce transmission of SARS-CoV-2. The extent to which these interventions are successful in stopping the spread have not been characterized in countries with distinct socioeconomic groups. We compared the effects of a partial lockdown on disease transmission among Kuwaitis $\left(P_{1}\right)$ and non-Kuwaitis $\left(P_{2}\right)$ living in Kuwait.

Methods: We fit a modified metapopulation SEIR transmission model to reported cases stratified by two groups to estimate the impact of a partial lockdown on the effective reproduction number $\left(\mathcal{R}_{e}\right)$. We estimated the basic reproduction number $\left(\mathcal{R}_{0}\right)$ for the transmission in each group and simulated the potential trajectories of an outbreak from the first recorded case of community transmission until 12 days after the partial lockdown. We estimated $\mathcal{R}_{e}$ values of both groups before and after the partial curfew, simulated the effect of these values on the epidemic curves and explored a range of cross-transmission scenarios.

Results: We estimate $\mathcal{R}_{e}$ at 1.08 (95\% Cl: 1.00-1.26) for $\mathrm{P}_{1}$ and 2.36 (2.03-2.71) for $\mathrm{P}_{2}$. On March 22nd, $\mathcal{R}_{e}$ for $\mathrm{P}_{1}$ and $P_{2}$ are estimated at $1.19(1.04-1.34)$ and $1.75(1.26-2.11)$ respectively. After the partial curfew had taken effect, $\mathcal{R}_{e}$ for $\mathrm{P}_{1}$ dropped modestly to $1.05(0.82-1.26)$ but almost doubled for $\mathrm{P}_{2}$ to 2.89 (2.30-3.70). Our simulated epidemic trajectories show that the partial curfew measure greatly reduced and delayed the height of the peak in $P_{1}$, yet significantly elevated and hastened the peak in $P_{2}$. Modest cross-transmission between $P_{1}$ and $P_{2}$ greatly elevated the height of the peak in $P_{1}$ and brought it forward in time closer to the peak of $P_{2}$.
\end{abstract}

\footnotetext{
* Correspondence: f.khadadah@mail.utoronto.ca;

abdullah.alshammari@ku.edu.kw

${ }^{\dagger}$ Fatima Khadadah and Abdullah A. Al-Shammari contributed equally to this work.

${ }^{1}$ Department of Medicine, University of Toronto, Toronto, ON, Canada

${ }^{3}$ Department of Mathematics, Faculty of Sciences, Kuwait University, Khaldiya, Kuwait

Full list of author information is available at the end of the article
}

(c) The Author(s). 2021 Open Access This article is licensed under a Creative Commons Attribution 4.0 International License, which permits use, sharing, adaptation, distribution and reproduction in any medium or format, as long as you give appropriate credit to the original author(s) and the source, provide a link to the Creative Commons licence, and indicate if changes were made. The images or other third party material in this article are included in the article's Creative Commons licence, unless indicated otherwise in a credit line to the material. If material is not included in the article's Creative Commons licence and your intended use is not permitted by statutory regulation or exceeds the permitted use, you will need to obtain permission directly from the copyright holder. To view a copy of this licence, visit http://creativecommons.org/licenses/by/4.0/ The Creative Commons Public Domain Dedication waiver (http://creativecommons.org/publicdomain/zero/1.0/) applies to the data made available in this article, unless otherwise stated in a credit line to the data. 
Conclusion: Our results indicate and quantify how the same lockdown intervention can accentuate disease transmission in some subpopulations while potentially controlling it in others. Any such control may further become compromised in the presence of cross-transmission between subpopulations. Future interventions and policies need to be sensitive to socioeconomic and health disparities.

Keywords: COVID-19, Non-pharmaceutical interventions, Mathematical modeling, Socioeconomic disparities

\section{Background}

On February 20th, with zero reported cases of coronavirus disease 2019 (COVID-19) in Kuwait and only two reported deaths in neighboring Iran [1], the State of Kuwait ordered immediate closure of its shared borders and subsequent evacuation of its citizens from Iran [2]. The first group of evacuees from Mashhad, Iran were asked to self-isolate at home while the second group of evacuees from Tehran and Qom were placed in institutional quarantine. Estimates put the true number of cases in Iran at the time to be in the range of 18,300 (95\% confidence interval: 3770 to 53,470) [3]. This intervention was subsequently followed by further border control measures, closures of schools, non-essential businesses and public gathering spots, cessation of all commercial flights and, eventually a partial lockdown on March 22nd 2020 [4-6].

Since the beginning of the epidemic, without effective pharmaceutical interventions available to prevent or treat COVID-19, countries largely rely on nonpharmaceutical interventions (NPIs) to reduce disease transmission [7, 8]. Early combined NPIs were shown to reduce disease transmission and delay peak death rates. Additionally, timing of NPI implementation appears to correlate with peak death rates [8]. Nations which were able to implement early containment measures such as Taiwan, Singapore, Japan and Hong Kong all seemingly were flattening the epidemic curve in the first few months of the pandemic [9]. Despite lags in testing, it was thought that Kuwait would pursue a similar trajectory due to its aggressive early action.

Evidence is accumulating that viral spread is unequal and preys preferentially on lower socioeconomic classes [10-12], but it is unclear how NPIs implemented in various countries are playing a role in this regard. Models of disease transmission thus far have been homogenous and have not yet accounted for these important heterogeneities [13]. Kuwait and the rest of the Gulf States have a unique demographic profile. Nearly $70 \%$ of the 4.8 million people living in Kuwait are non-Kuwaiti, and largely represent migrant workers of lower socioeconomic status. The profile of the Non-Kuwaiti population is predominantly male (69\%), poorly educated (68\% below secondary level education), and relatively young (median age group 30-34) [14] (Table 1).
In this study, we quantify the differences in viral transmission dynamics of SARS-CoV-2 between Kuwaiti nationals and non-Kuwaitis living in Kuwait using nationality as a surrogate for socioeconomic status. We also look at how NPIs affected transmission dynamics in each group.

\section{Methods}

To explore the impact of heterogeneities in transmission dynamics in Kuwait, we fitted a metapopulation transmission dynamic model to a dataset on reported cases stratified by two socioeconomic groups (Table 1 and Fig. $\mathrm{S} 1 \mathrm{a}$ and $\mathrm{b}$ in the Supplementary Material). The dataset contained daily numbers of reported confirmed cases from the two groups.

Publicly-available data on COVID-19 cases was collected daily from verified and official government sources $[15,17]$. The dataset included cases from the first reported case of COVID-19 on February 24th, 2020 until May 12th, 2020. The model was fitted to case numbers up to April 20th, 2020 in order to disentangle the impact of the partial curfew from other drastic interventions that were implemented past this date. Information was limited to the number of confirmed cases, travel history, nationality, critical cases, recoveries, and deaths.

Information about population density, residential units (houses and apartments) and occupation were obtained from the online Statistics Service System at the Public Authority for Civil Information (PACI); last updated on 21 December, 2019 [14]. To create maps depicting the geographic density of the two populations as well as the residential units we used ArcGIS Pro version 2.5.1 by Esri Inc. The district polygons were obtained from OpenStreetMaps [18].

\section{Model}

The modified metapopulation SEIR model divides the population into two distinct groups: Subpopulation 1 $\left(\mathrm{P}_{1}\right)$ of presumed higher socioeconomic status and Subpopulation $2\left(\mathrm{P}_{2}\right)$ of presumed lower socioeconomic status, who are vastly overrepresented by non-Kuwaitis (Table 1). We analyze the disease transmission by using a modified SEIR model that describes the epidemiological characteristics of COVID-19. The model divides individuals within each subpopulation into the following compartments: susceptible (S), exposed but not 
Table 1 Socioeconomic differences between Kuwaiti and non-Kuwaiti residents in Kuwait in 2019

\begin{tabular}{|c|c|c|}
\hline & Kuwaitis $\left(P_{1}\right)$ & Non-Kuwaitis $\left(\mathrm{P}_{2}\right)$ \\
\hline Population - N (\%) & $1,432,045(30.0)$ & $3,344,362(70.0)$ \\
\hline \multicolumn{3}{|c|}{ Average Monthly Income in Public Sector $[15,16]$ - Kuwaiti Dinar (USD) } \\
\hline Female & $1279(4135)$ & $666(2153)$ \\
\hline Male & $1807(5841)$ & $726(2347)$ \\
\hline \multicolumn{3}{|c|}{ Average Monthly Income in Private Sector $[15,16]$ - Kuwaiti Dinar (USD) } \\
\hline Female & 866 (2799) & $387(1251)$ \\
\hline Male & $1417(4581)$ & $271(876)$ \\
\hline \multicolumn{3}{|l|}{ Education - N (\%) } \\
\hline Below secondary school & $521,699(36.4)$ & $2,265,394(67.7)$ \\
\hline Secondary school and above & $481,407(33.6)$ & $552,725(16.5)$ \\
\hline Unknown & $428,939(30.0)$ & $52,6243(15.7)$ \\
\hline \multicolumn{3}{|l|}{ Occupation $^{*}-\mathrm{N}(\%)$} \\
\hline Manual work & $21,288(4.0)$ & $1,148,897(44.4)$ \\
\hline Non-manual work & $568,843(96.2)$ & $1,291,496(50.0)$ \\
\hline Not stated & $1354(0.2 \%)$ & $145,865(5 \cdot 6 \%)$ \\
\hline Healthcare Access & Free medical, dentistry and pharmacy care & Fee-for-service \\
\hline Social Welfare & Available & Not available \\
\hline Public Housing & Subsidized & Not available \\
\hline
\end{tabular}

"Occupations as per International Standard Classification of Occupations. Grouped under manual work are agriculture and fishery workers, craft and related trades work, production monitoring and elementary occupations. Under non-manual are managers, professionals, associate professionals, clerk and sales services workers. Population, education and income data sourced from PACI [14]

infectious (E), asymptomatic infectious $\left(\mathrm{I}_{\mathrm{A}}\right)$, presymptomatic infectious $\left(\mathrm{I}_{\mathrm{P}}\right)$, symptomatic infectious $\left(\mathrm{I}_{\mathrm{S}}\right)$, and removed $(\mathrm{R})$. The progression through the different compartments is described by key durations that are known to characterize the infection transmission dynamics of COVID-19 (Table A1 in Supplementary Material). Our model structure is presented in Fig. 1 and details about the model equations and its parametrization are presented in the Supplementary Material.

Given that the population is almost fully susceptible early in the outbreak (due to a relatively small number of cases), we assume the transmission rate for each subpopulation, $\beta$, is only affected by the implementation of a partial lockdown during this period. Hence, we assume that the transmission rate is a function of time $\beta(t)=$ $\kappa(t) \beta_{0}$, where $\beta_{0}$ is the baseline transmission rate (i.e. without a partial lockdown) and $\kappa(t)$ is a positive step function that models the scaling by which a control measure may reduce $(\kappa<1)$ or increase $(\kappa>1)$ the transmission rate:

$$
\kappa(t)=\left\{\begin{array}{c}
1, \text { Before lockdown } \\
\kappa, \text { During lockdown }
\end{array}\right.
$$

We describe the interaction between the two subpopulations using two parameters, $\beta_{12}$ and $\beta_{21}$, to model the successful transmission occurring upon cross-contact between individuals of $\mathrm{P}_{1}$ and $\mathrm{P}_{2}$. The average interaction between socioeconomic groups is modeled by a $2 \times 2$ transmission matrix, which describes the disease transmission between and within subpopulations:

$$
\left(\begin{array}{ll}
\beta_{11} & \beta_{12} \\
\beta_{21} & \beta_{22}
\end{array}\right)
$$

This transmission matrix provides a convenient means for capturing the mixing between and within the subpopulations, with each entry value $\beta_{i j}$ modeling the average transmission of the disease from individuals in subpopulation $j$ to individuals in subpopulation $i$. In this formulation, we assume that there exists an epidemiological cross-coupling between the two socioeconomic groups with negligible cross-migration. The mixing pattern is assumed to be strongly assortative to reflect the fact that 1) individuals interact strongly and preferentially within their socioeconomic group and 2) migrant workers reside in separate geographical locations. In particular, migrant workers are assumed to only make short-lived visits to work in areas populated by the $\mathrm{Ku}$ waiti subpopulation. These patterns dictate that the between-subpopulation transmission parameters $\beta_{12}$ and $\beta_{21}$ (cross-transmission rates) are considerably smaller than the within-subpopulation transmission parameters $\beta_{11}$ and $\beta_{22}$. Further, individuals from both 


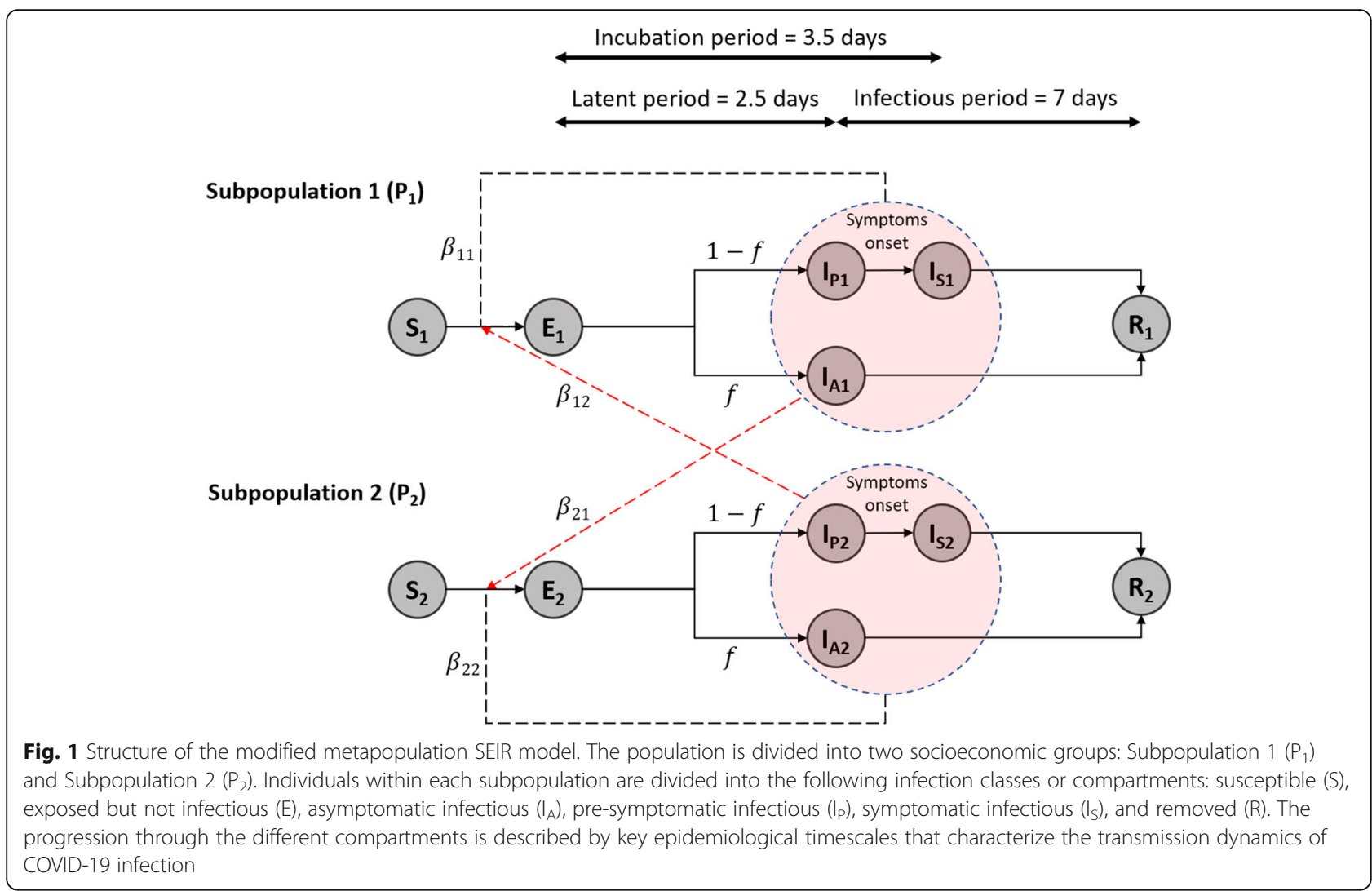

subpopulations are assumed to have equal cross-contact rates and response to the infection which, in turn, dictates that the between-subpopulation interaction is symmetric, i.e. $\beta_{12}=\beta_{21}$. For convenience, these crosstransmission rates are taken as free adjustable parameters to explore their effect on peak and cumulative incidence of COVID-19 infections, with our model results checked for sensitivity (see Table A1). The other transmission rates, $\beta_{11}$ and $\beta_{22}$, capture the disease dynamics within subpopulations and are assumed to reflect the bulk of the early transmission dynamics in Kuwait where the observed social mixing patterns dictate that early transmission is effectively decoupled. Hence, the impact of the partial lockdown is expected to be entirely captured by changes to the baseline values of these withinsubpopulation transmission rates. We model these changes by allowing each subpopulation to have its own scaling factor, $\kappa$, which we estimate by fitting our model to the numbers of early confirmed cases in each subpopulation.

We assume the outbreak started in both subpopulations with a single infectious case on February 24, 2020 and with both subpopulations being initially susceptible. To capture the initial heterogeneity in contact structure, we estimate a basic reproduction number $\left(\mathcal{R}_{0}\right)$ for each subpopulation by fitting their early outbreak data to an individual modified SEIR model [19]. Similarly, we quantify the impact of imposing a partial lockdown on March 22, 2020 by estimating the effective reproduction number $\left(\mathcal{R}_{e}\right)$ for each subpopulation during the lockdown period. We note here that the impact of the partial lockdown is inherently characterized by the scaling factor $\kappa$, where $\mathcal{R}_{e}=\kappa \mathcal{R}_{0}$. In other words, $\kappa$ plays the role of an effectiveness parameter for the intervention, with values less than 1 characterizing the intervention as effective.

Our results for both reproductive numbers are directly derived from the estimation of two unknown model parameters for each subpopulation: $\beta_{0}$ and $\kappa$. In short, we derive maximum likelihood estimates (MLE) of these unknown parameters by assuming the observed numbers of reported cases follow a negative binomial process, thus allowing for estimates of model uncertainty. Optimization was carried out using the Nelder-Mead method and parameter uncertainty was represented by quantile-based $95 \%$ confidence intervals (CI). Our estimates of the baseline and effective transmission rates are then used to simulate the epidemic curves of each subpopulation and under various cross-transmission scenarios. All of our simulations, parameter estimation and model fitting were run in the $\mathrm{R}$ software environment [20] as described elsewhere [19].

In Kuwait, COVID-19 transmission outside of the home is mainly observed in healthcare facilities and 
essential businesses. We assume that these are the places where transmission occurs from individuals living in COVID-19 reservoirs $\left(\mathrm{P}_{2}\right)$ to those not living there $\left(\mathrm{P}_{1}\right)$. We explore the effect of this cross-transmission by simulating the epidemic curves for $\beta_{12}=\beta_{21}=0.01$ or 0.02 . Here $\beta_{12}=0$ models the situation where isolation of infection reservoirs is stringent. Increasing this value simulates the situation where some individuals from $\mathrm{P}_{2}$ are allowed to work in healthcare facilities and essential businesses.

The data and codes that support the findings of this study are fully available from the corresponding author, upon reasonable request.

\section{Results}

We present our estimates of the reproduction numbers in Table 2. The basic reproduction numbers for $\mathrm{P}_{1}\left(\mathcal{R}_{0,1}\right.$

) and $\mathrm{P}_{2}\left(\mathcal{R}_{0,2}\right)$ are 1.08 (95\% CI: $\left.1.00-1.26\right)$ and 2.36 (2.03-2.71), respectively. Prior to the partial curfew, the effective reproduction numbers were 1.19 (1.04-1.34) and $1.75(1.26-2.11)$ for $P_{1}$ and $P_{2}$, respectively. Imposing a partial curfew greatly reduced the reproduction number to $1.05(0.82-1.26)$ in $\mathrm{P}_{1}$, while significantly increasing it to $2.89(2.30-3.70)$ in $\mathrm{P}_{2}$. These results suggest that the effects of lockdowns vary across socioeconomic groups. After imposing additional geographic isolation on $\mathrm{P}_{2}$ combined with focused testing, contact-tracing and isolation the effective reproduction number was reduced to $1.51(1.13-1.96)$. Over this time period, death rates for $P_{1}$ were 5.59 per million inhabitants, compared to 9.57 per million inhabitants for $\mathrm{P}_{2}$.

Figure $2 \mathrm{a}$ and $\mathrm{b}$ shows the subpopulation and building densities in the country. Areas of increased population density, in particular that of the non-Kuwaiti population correlate geographically with increased housing density and are almost interposable. Figure 3 highlights the daily number of cases before and after the institution of the lockdown in the two populations.

Simulations based on these reproduction numbers model the effect of a partial curfew on the epidemic curves (Fig. 4). Our simulations show that the two subpopulations had distinct daily incidence dynamics prior to the partial curfew, with $P_{1}$ showing a significantly lower and delayed peak incidence (about 8 times lower than $\mathrm{P}_{2}$ ). After imposing the partial curfew, the two peaks diverge further with $\mathrm{P}_{2}$ experiencing a significantly higher and earlier peak than $P_{1}$ (more than 200 times higher than $\mathrm{P}_{1}$ ). In particular, the partial curfew is predicted to have had the effect of averting $21.5 \%$ of the total COVID-19 infections and reducing the peak incidence by $91.4 \%$ in subpopulation 1 (Figs. $4 \mathrm{~b}$ and c). In contrast, had there not been an implementation of a partial curfew on subpopulation 2, our model predicts that $22 \%$ of this population would not have been infected (Fig. 4), which is equivalent to averting COVID-19 peak incidence by $62.5 \%$ in subpopulation 2 (Fig. 4). In the presence of increasing cross-transmission, the flattening effect of the NPI on $P_{1}$ is compromised, suggesting that strategies curbing the epidemic outbreak in one group may become less effective if cross-transmission is not sufficiently controlled.

\section{Discussion}

We demonstrate how a curfew intervention was associated with a greater negative impact of COVID-19 in non-Kuwaiti populations of lower socio-economic status compared to the Kuwaiti population due to an increased in-house contact rate under curfew. A recent study by Hamadah and colleagues further demonstrated a twofold increased odds of death and ICU admission in the non-Kuwaiti population when compared to the Kuwaiti population in Kuwait [21]. Socioeconomic and demographic factors such as ethnicity, population density, housing conditions and education level are known to be associated with increased transmission and mortality from viral illness [22-25]. The same trend appears to be manifesting in the COVID-19 pandemic globally, with a disproportionate burden of cases and mortality in lower socioeconomic groups [10-12]. These are the same groups that tend to disproportionately suffer from the unintended consequences of NPIs [26, 27].

Our study is corroborated by the COVID-19 experience in Singapore. A study by Koo and colleagues evaluating a Singaporean population recommended a comprehensive intervention involving quarantine, school closures and workplace distancing to reduce SARS-CoV2 infection once community transmission was established. They did, however, note that at $\mathcal{R}_{0}>2$, certain dense residential clusters in Singapore showed strong viral persistence despite these measures and importantly, their study did not take into account migrant workers

Table 2 Basic and effective reproduction numbers for $P_{1}$ and $P_{2}$ (higher and lower socioeconomic groups respectively)

\begin{tabular}{|c|c|c|c|c|}
\hline \multirow[b]{2}{*}{ Subpopulation } & \multicolumn{3}{|l|}{ Effective reproduction number, $\mathcal{R}_{e}$} & \multirow{2}{*}{$\begin{array}{l}\text { Basic } \\
\text { reproduction } \\
\text { number, } \mathcal{R}_{0}\end{array}$} \\
\hline & 25 Feb - 22 Mar (Prior to partial lockdown) & 22 Mar - 3 Apr (After partial lockdown) & 19-Apr-2020 & \\
\hline$P_{1}$ & $1.19(1.04-1.34)$ & $1.05(0.82-1.26)$ & $1.02(0.91-1.14)$ & $1.08(1.00-1.26)$ \\
\hline$P_{2}$ & $1.75(1.26-2 \cdot 11)$ & $2 \cdot 89(2 \cdot 30-3 \cdot 70)$ & $1.51(1 \cdot 13-1.96)$ & $2 \cdot 36(2.03-2 \cdot 71)$ \\
\hline
\end{tabular}

* 95\% Confidence Interval (Cl) values are given in parentheses. $P_{1}$ and $P_{2}$ are the subpopulations of higher and lower socioeconomic status, respectively 


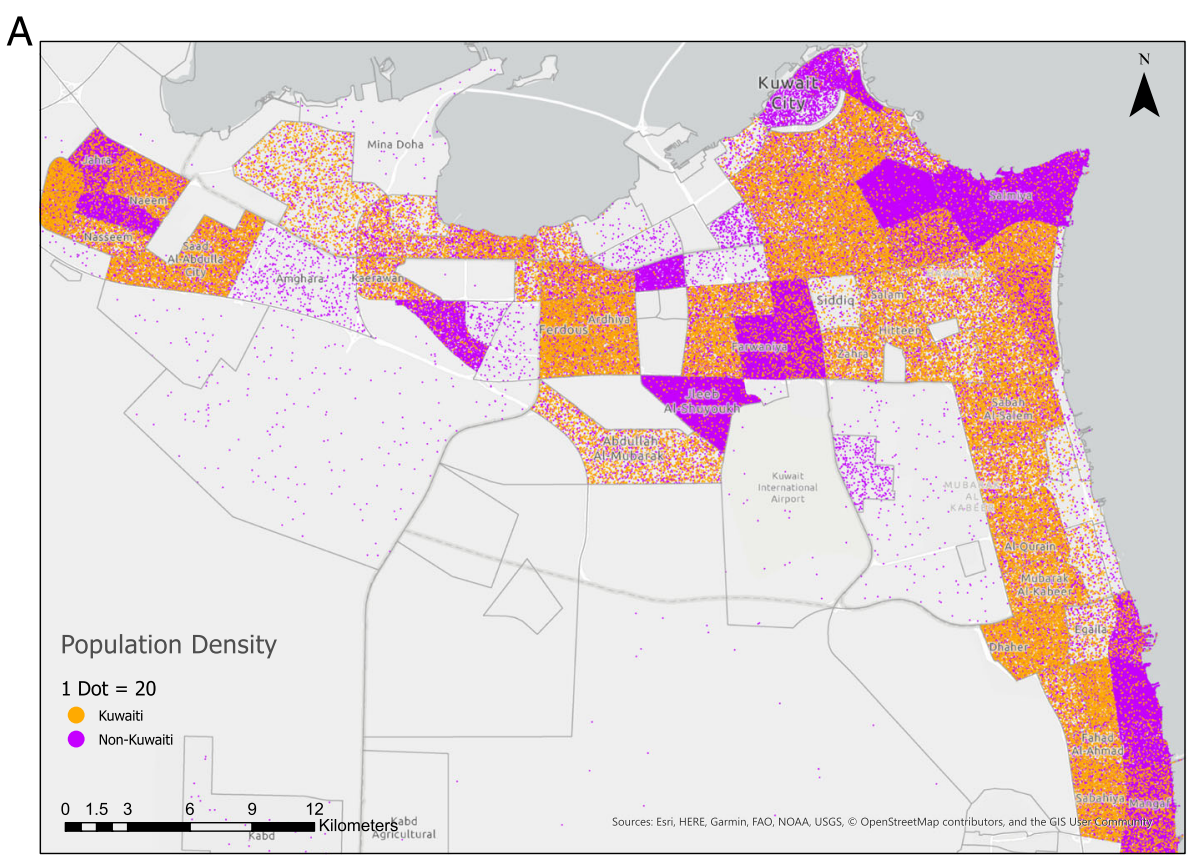

$\mathrm{B}$

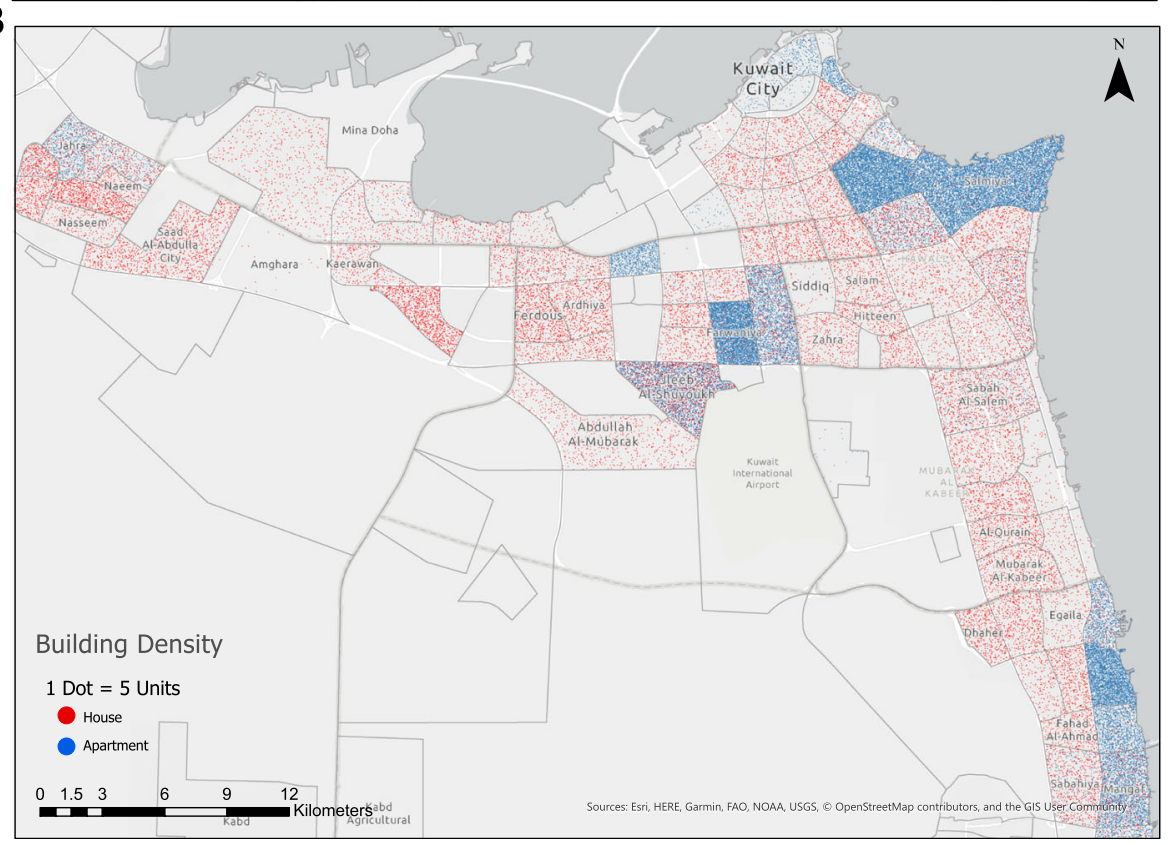

Fig. 2 Spatial structure of the population in Kuwait. a A geographical density distribution of the Kuwaiti and Non-Kuwaiti subpopulations. b A spatial density of the housing buildings by districts in Kuwait

who travel daily from Malaysia to Singapore [28]. Despite very successful efforts at dealing with the initial spread of infection, a second resurgence of infections was challenging for Singapore to cope with as the majority of cases were found amongst migrant workers living in dense dormitories [29].

Another epidemiological study from Wuhan, China demonstrated a reduction in effective reproduction number of SARS-CoV-2 after introduction of quarantine and other measures from above 3.0 at baseline to less than 0.3 after March 1st [30]. Historically, early implementation of multiple interventions are associated with reduced disease transmission and death rates [8]. While there is clear epidemiological rationale supporting quarantine as a measure for limiting viral transmission, the evidence base continues to be weak due to difficulties in carrying out such studies [31]. Some data has suggested that while home quarantine can reduce community 


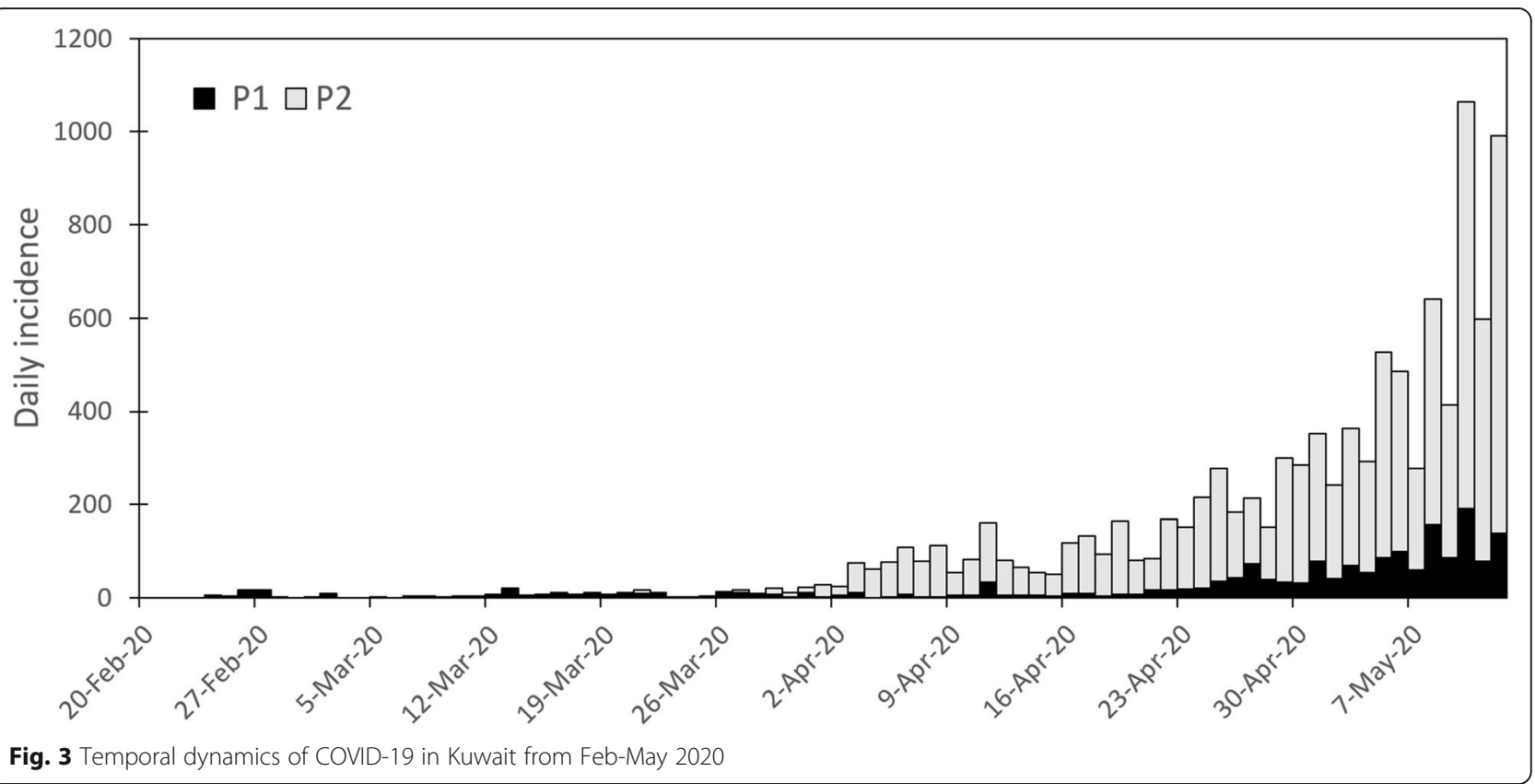

spread, it may also lead to an increase in infection of cohabitants [31-33]. In the current epidemic, the attack rate of SARS-CoV-2 in households appears to be in the range of $10-16 \%$; however, little is known about the socioeconomic factors of these households, and we would expect higher attack rates in crowded living conditions [34-36].

In our study, after the institution of a partial lockdown, there was a rise in $\mathcal{R}_{e}$ of non-Kuwaitis as well as a greater variability in the confidence interval. This may be explained by Kuwaitis and non-Kuwaitis of higher socioeconomic status having greater ability to stay at home and institute a measure of physical distancing within their homes. On the other hand, workers who are more likely to live in crowded dormitories were now spending more time in close proximity in indoor environments without wearing masks. Had migrant workers been able to physically distance themselves and effectively practiced universal masking, the incidence of infection could have decreased. However, cohabitants who were shift workers could no longer stagger their time at home as a direct result of the partial lockdown and were forced into closer proximity. This, in addition to threats to food and livelihood security, likely inflamed the situation [37]. Indeed, recent evidence based on spatiotemporal data suggested that the exponential phase of the epidemic started in late March, after the lockdown was in place [38]. The same study highlighted the benefits of introducing spatially heterogeneous interventions whereby additional control measures were localized to the migrant hotspots resulting from the partial lockdown.

Another important observation is the modest decrement in $\mathcal{R}_{e}$ in Kuwaitis after the lockdown. For such an extreme measure with such significant economic connotations, we would have expected a greater effect, such as a reduction of $\mathcal{R}_{e}$ below 1.0, which signals a receding disease transmission among Kuwaitis. This may be explained by the proximity of Kuwaitis and non-Kuwaitis, even throughout the lockdown [24, 25]. Given that many non-Kuwaitis provide essential services to the country, there is a strong possibility that infection was transmitted to Kuwaiti nationals despite lockdown measures in place. It follows from this that disparities within a population lead to worsening of disease transmission for all components of society, a more prolonged pandemic phase and potentially heavier impacts on the economy as a whole. We hypothesize that more equitable societies are likely to fare better (and more predictably) in this pandemic than less equitable ones.

Significant attempts were made to ease the burden of COVID-19 in non-Kuwaiti populations. Healthcare was declared free of charge for non-Kuwaitis with COVID19 [39], funds were raised to support families and workers affected by the pandemic and field hospitals and quarantine facilities were established in the most densely populated areas. Importantly, the crisis has led to a heightened media focus on human trafficking and labor laws as important culprits in the poor living conditions of workers. This has resulted in a two-pronged government policy: pursue and punish lawbreakers, and provide amnesty and repatriation for workers trapped without valid papers [37, 38, 40]. These attempts came to national attention during the pandemic to help limit disease spread by caring for vulnerable populations and supporting a more general public health framework. 
(A)
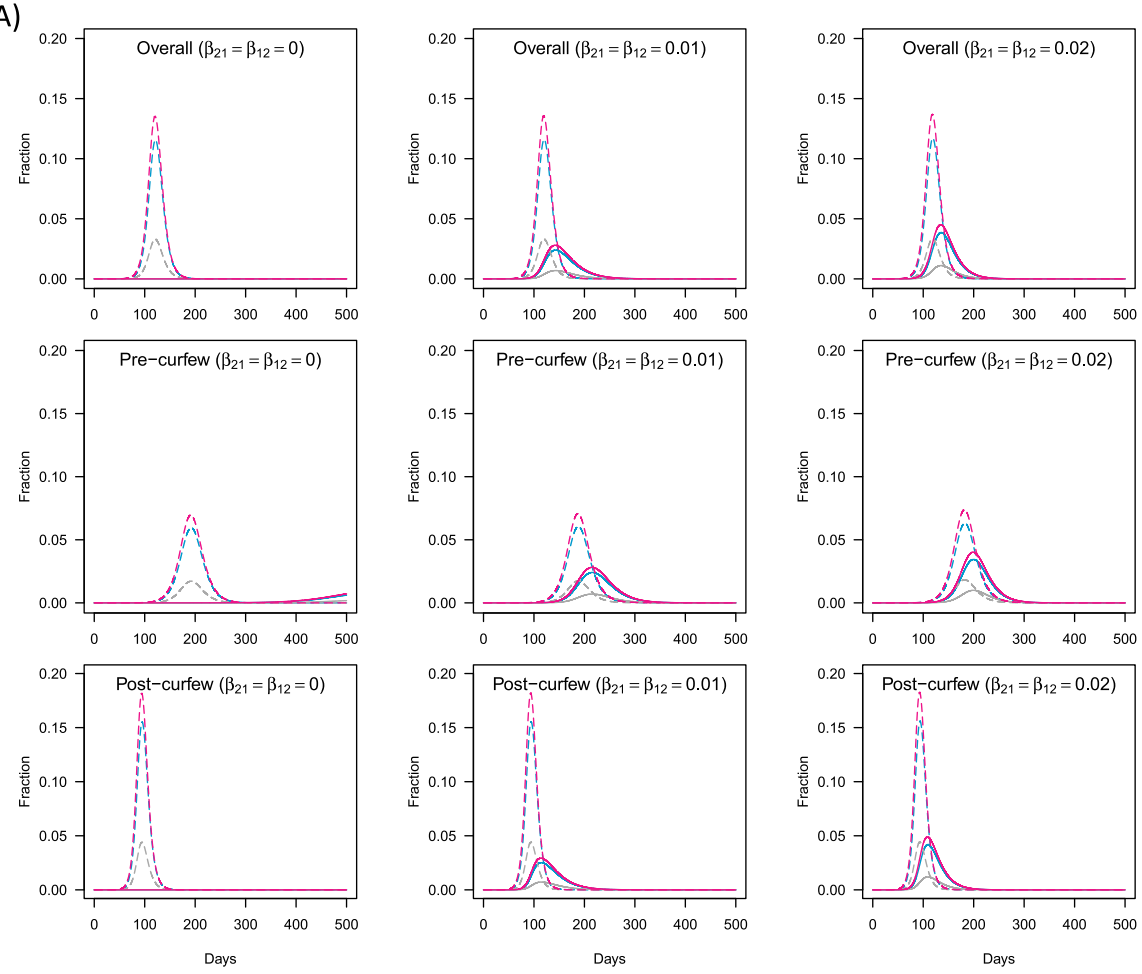

(B)

(C)

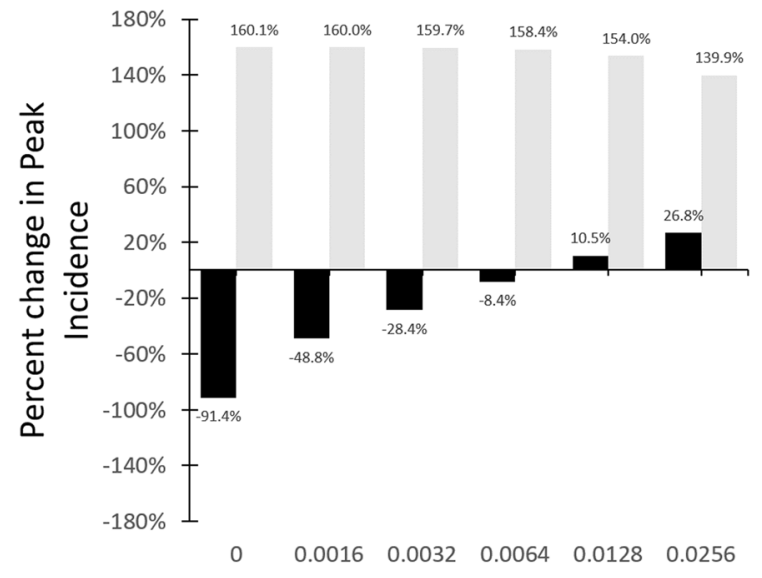

$\beta 12, \beta 21$

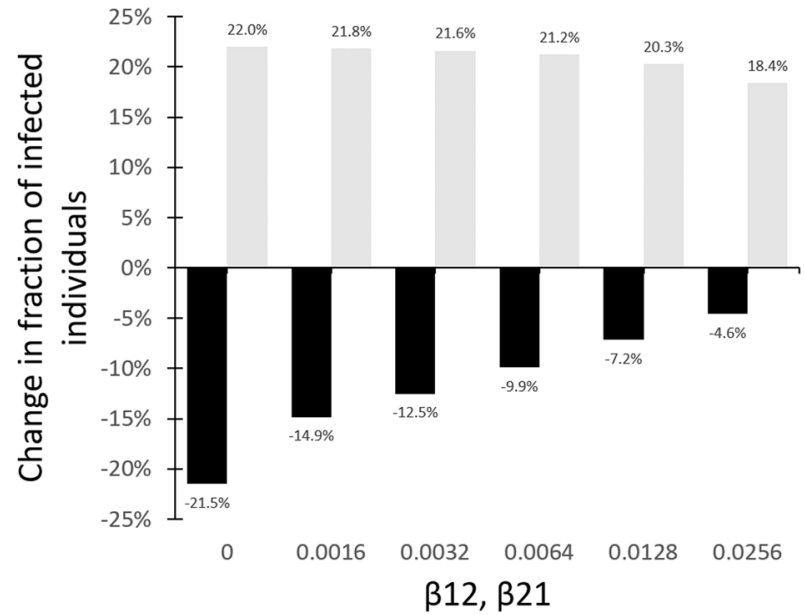

Fig. 4 a Effect of partial curfew on the epidemic curves. Model simulations of the daily infection incidence for $P_{1}$ and $P_{2}$ (higher and lower socioeconomic groups respectively) before and after the partial curfew. (Overall) Simulations based on the basic reproduction numbers $\mathcal{R}_{0,1}=1$ .08 and $\mathcal{R}_{0,2}=2 \cdot 36$. (Pre-curfew) Simulations based on pre-curfew reproduction numbers $\mathcal{R}_{e, 1}=1 \cdot 19$ and $\mathcal{R}_{e, 2}=1 \cdot 75$. (Post-curfew) Simulations based on post-curfew reproduction numbers $\mathcal{R}_{e, 1}=1 \cdot 05$ and $\mathcal{R}_{e, 2}=2 \cdot 89$. Cross-transmission is modeled by using $\beta_{12}=\beta_{12}=0$, $0.01,0.02$ to simulate an increase in uncontrolled transmission (or leak) from individuals in $P_{2}$ to $P_{1}$ and vice versa. Solid lines refer to $P_{1}$ and dashed lines refer to $P_{2}$. Line colors refer to different infection states: Grey=asymptomatic infections, pink = pre-symptomatic \& symptomatic infections, and blue = symptomatic infections. $\mathbf{b}$ - $\mathbf{c}$ Change in the peak and overall infections of COVID-19 in $P_{1}$ and $P_{2}$ under different crosstransmission scenarios. From left to right, with increasing symmetric cross-transmission between $P_{2}$ and $P_{1}$ (i.e. $\beta_{12}=\beta_{12}$ ), less and less cases are averted in $\mathrm{P}_{1}$ and the effect of the NPI on peak incidence is gradually blunted. The maximum averted COVID-19 infections in $\mathrm{P}_{1}$ is found in the absence of cross-transmission. In this case, the peak incidence is reduced by $91.4 \%$ and the total infections are averted by $21.5 \%$. Black color refers to $P_{1}$ and grey color refers to $P_{2}$. (Vertical axes have been amended to highlight the differences in the effect of the intervention)

\section{Limitations}

Our modeling results should be interpreted qualitatively rather than taken as projections of the epidemic curve and associated burdens such as mortality. Models are simplifications of a complex reality which, in our case, is concerned with an emergent and complex infectious disease. 
Tackling such a complexity in a meaningful way requires both a sufficient understanding of the disease dynamics and sustainable access to a range of important datasets. Our analyses, however, were restricted by limitations in data availability which may be related to how data is collected and shared publicly. At the time of writing, concise information on a) daily testing rates, b) random testing, c) contact tracing and isolation, d) location, demographics and clinical manifestation of all cases was not made publicly available. Without such data, our analyses could not dissociate the effect of the infectivity of different modes of the disease from the effectiveness parameter $\mathrm{\kappa}$. In addition, as the pandemic progressed, information about nationality became more restricted. We were unable to divide nonKuwaiti cases into those who worked in labor and those who were more skilled with potentially higher socioeconomic status. We believe that our data largely reflects manual workers given their initial clustering in highly dense worker dormitories and areas. Finally, around 750, 000 non-Kuwaitis (members of Subpopulation 2) are livein domestic workers. However, this argues more strongly for our case, as their dilutionary effect likely blunted the calculated rise in $\mathcal{R}_{e}$ amongst $\mathrm{P}_{2}$.

Pre-symptomatic and asymptomatic transmissions have been confirmed to play an important role in driving SARS-CoV-2 outbreaks, particularly in geographic areas where case ascertainment and testing rates or scope are low. Physical distancing mandates in such areas are believed to be an important NPI measure to control the progression of the outbreak. However, in our case, the living conditions of the migrant worker subpopulation led to a paradoxical outcome. We have not attempted to explicitly model physical distancing via compartmental subdivision within each subpopulation. Instead we chose parsimony by accounting for such a measure in terms of changes in the contact frequency as captured by the effectiveness parameter $\kappa$.

While we acknowledge that at the earliest stages of the outbreak, surveillance was mostly symptom-based, we believe that early in the outbreak the contact-tracing capacity in Kuwait may have been sufficiently effective in offsetting this and hence capturing asymptomatic cases. It is also widely acknowledged that a transparent tracking and reporting of data from random testing and contact tracing is vital for quantifying the levels of community transmission, acquired immunity and population interaction. Such unavailable data is key for informing transmission models, particularly when there is uncertainty about the relative importance of the different transmission routes of SARS-CoV-2.

\section{Conclusions}

We demonstrate how lockdown policies can paradoxically facilitate COVID-19 transmission among those who cannot practice physical distancing in non-optimal living conditions. To be effective, interventions intended to promote physical distancing and isolation need to account for existing socioeconomic and health disparities.

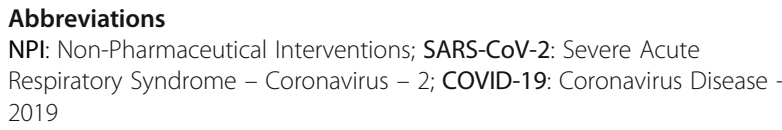

\section{Supplementary Information}

The online version contains supplementary material available at https://doi. org/10.1186/s12889-021-10984-6.

\section{Additional file 1. Supplementary Material.}

\section{Acknowledgements}

We are grateful for the volunteers at coronamapskw.com for their assistance with data collection including Dr. Maryam Al-Sarraji, Adnan N. Al-Abbar and Fatemah Alnajdi. As well as Dr. Saad Alsharrah for his map-making expertise. We are also grateful to the Public Authority for Civil Information for making demographic information accessible on their website.

\section{Authors' contributions}

AAA and FK conceived and designed the research. FK, DA and SA collected the data. AAA analyzed the data and developed the model. All authors helped interpret model results. AAA, FK, AA and DA prepared the Figs. FK, AAA, AA, BA and DA drafted the manuscript. AAA, B Alahmed, FK, SNA and $\| B$ reviewed and edited the manuscript. All authors revised and approved the final version of the manuscript.

\section{Funding}

None.

\section{Availability of data and materials}

The datasets generated and/or analyzed during the current study are publicly available datasets. Data related to the COVID-19 confirmed cases and deaths in the state of Kuwait are available in an online repository at https://github.com/coronamapskw. Data about population demographics were obtained from the Online Statistics Service System at the Public Authority for Civil Information and are available online in Kuwait only via http:// stat.paci.gov.kw/englishbuildreports/. All data and codes that support the findings of this study are fully available from the corresponding author, upon reasonable request.

\section{Declarations}

Ethics approval and consent to participate Not applicable.

\section{Consent for publication}

Not applicable.

\section{Competing interests}

The authors have nothing to disclose.

\section{Author details}

${ }^{1}$ Department of Medicine, University of Toronto, Toronto, ON, Canada. ${ }^{2}$ Division of Medical Oncology and Hematology, Princess Margaret Cancer Centre, 610 University Ave, 700U 6W458, Toronto, ON M5G 2M9, Canada. ${ }^{3}$ Department of Mathematics, Faculty of Sciences, Kuwait University, Khaldiya, Kuwait. ${ }^{4}$ Dasman Diabetes Institute, Dasman, Kuwait. ${ }^{5}$ Department of Medicine, Adan Hospital, Ministry of Health, Al-Ahmadi, Kuwait. ${ }^{6}$ Department of Information Science, College of Life Sciences, Kuwait University, Sabah Al-Salem University City, Sabah Al-Salem, Kuwait. ${ }^{7}$ Department of History, College of Arts, Kuwait University, Sabah Al-Salem University City, Sabah Al-Salem, Kuwait. ${ }^{8}$ Carnegie Middle East Center, Beirut, Lebanon.

${ }^{9}$ Department of Surgery, Faculty of Medicine, Kuwait University, Jabriya, 
Kuwait. ${ }^{10}$ Department of Environmental Health, Harvard T.H. Chan School of Public Health, Harvard University, Boston, MA, USA.

\section{Received: 28 July 2020 Accepted: 5 May 2021} Published online: 26 May 2021

\section{References}

1. World Health Organisation. Coronavirus disease 2019 (COVID-19) Situation Report - 31. Geneva, Switzerland; 2020. https://www.who.int/docs/defaultsource/coronaviruse/situation-reports/20200220-sitrep-31-covid-19. pdf?sfvrsn=dfd11d24_2. Accessed 24 April 2020.

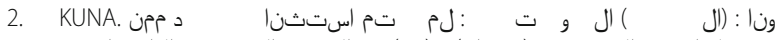

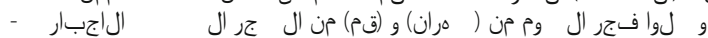

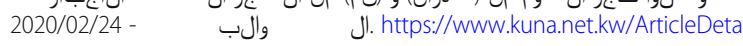
ils.aspx?id=2864468. Accessed 24 Apr 2020.

3. Tuite AR, Bogoch II, Sherbo R, Watts A, Fisman D, Khan K. Estimation of coronavirus disease 2019 (COVID-19) burden and potential for internationaldissemination of infection from Iran. Ann Intern Med. 2020; 172(10):699-701. https://doi.org/10.7326/M20-0696. Epub 2020 Mar 16.

4. KUNA : Kuwait gov't imposes partial curfew, extends holiday for two weeks - Mol - Government - 22/03/2020. https://www.kuna.net.kw/ArticleDetails.a spx?id=2880575\&language $=e n$. Accessed 11 May 2020.

5. KUNA : Kuwait gov't suspends commercial flights as of midnight March 13 Government - 11/03/2020. https://www.kuna.net.kw/ArticleDetails.aspx?id= 2876451\&language $=$ en. Accessed 11 May 2020.

6. KUNA : Kuwait extends school closure until March 26 - spokesman Government - 09/03/2020. https://www.kuna.net.kw/ArticleDetails.aspx?id= 2874997\&language=en. Accessed 11 May 2020.

7. Hartley DM, Perencevich EN. Public health interventions for COVID-19: emerging evidence and implications for an evolving public health crisis. JAMA. 2020;323(19):1908-9. https://doi.org/10.1001/jama.2020.5910.

8. Hatchett RJ, Mecher CE, Lipsitch M. Public health interventions and epidemic intensity during the 1918 influenza pandemic. Proc Natl Acad Sci U S A. 2007;104(18):7582-7. https://doi.org/10.1073/pnas.0610941104.

9. Legido-Quigley H, Asgari N, Teo YY, Leung GM, Oshitani H, Fukuda K, et al. Are high-performing health systems resilient against the COVID-19 epidemic? Lancet. 2020;395(10227):848-50. https://doi.org/10.1016/S01406736(20)30551-1.

10. White C, Nafilyan V. Coronavirus (COVID-19) related deaths by ethnic group, England and Wales - Office for National Statistics https://www.ons.gov.uk/ peoplepopulationandcommunity/birthsdeathsandmarriages/deaths/articles/ coronavirusrelateddeathsbyethnicgroupenglandandwales/2march2020to10a pril2020. Accessed 13 May 2020.

11. Chung H, Fung K, Ferreira-Legere L, Chen B, Ishiguro L, Kalappa G, et al. COVID-19 Laboratory Testing in Ontario: Patterns of Testing and Characteristics of Individuals Tested, as of April 30, 2020. . COVID-19 Laboratory Testing in Ontario: Patterns of Testing and Characteristics of Individuals Tested, as of April 30, 2020. Toronto, ON: ICES; 2020. https:// www.ices.on.ca/Publications/Atlases-and-Reports/2020/COVID-19-Labora tory-Testing-in-Ontario. Accessed 13 May 2020

12. Taylor K-Y. The black plague. The New Yorker https://www.newyorker.com/ news/our-columnists/the-black-plaque. Accessed 13 May 2020.

13. Twahirwa Rwema JO, Diouf D, Phaswana-Mafuya N, Rusatira JC, Manouan A, Uwizeye E, et al. COVID-19 across Africa: epidemiologic heterogeneity and necessity of contextually relevant transmission models and intervention strategies. Ann Intern Med. 2020;173(9):752-3. https://doi.org/10.7326/M20-2628.

14. Public Authority for Civil Information. Statistics Services System. Stat Designer. 2019. https://www.paci.gov.kw/stat/Default.aspx. Accessed 15 May 2020.

15. Central Agency for Information Technology. COVID 19 Updates .... Home. https://corona.e.gov.kw/En. Accessed 23 May 2020

16. Al-Shall Report. Kuwaitis, expats wage difference $114.9 \%$ in public sector. ARAB TIMES - KUWAIT NEWS. 2019. http://www.arabtimesonline. com/news/kuwaitis-expats-wage-difference-114-9-in-public-sector/. Accessed 11 May 2020.

17. Ministry of Health, Kuwait. وزار ال و (@KUWAIT_MOH) / Twitter. Twitter. https://twitter.com/kuwait_moh. Accessed 23 May 2020.

18. OpenStreetMap. OpenStreetMap. https://www.openstreetmap.org/. Accessed 23 May 2020
19. Al-Shammari AAA, Ali H, Al-Ahmad B, Al-Refaei FH, Al-Sabah S, Jamal MH, et al. Real-time tracking and forecasting of the COVID-19 outbreak in Kuwait: a mathematical modeling study. medRxiv. 2020;:2020.05.03. 20089771.

20. Core Team R. R: a language and environment for statistical computing. Vienna: R Foundation for Statistical Computing; 2014. https://www.rproject.org/.

21. Hamadah H, Alahmad B, Behbehani M, Al-Youha S, Almazeedi S, Al-Haddad M, et al. COVID-19 clinical outcomes and nationality: results from a Nationwide registry in Kuwait. BMC Public Health. 2020;20(1):1384. https:// doi.org/10.1186/s12889-020-09490-y.

22. Grantz KH, Rane MS, Salje H, Glass GE, Schachterle SE, Cummings DAT. Disparities in influenza mortality and transmission related to sociodemographic factors within Chicago in the pandemic of 1918. Proc Natl Acad Sci U S A. 2016;113(48):13839-44. https://doi.org/10.1073/pnas.1 612838113

23. Quinn SC, Kumar S. Health inequalities and infectious disease epidemics: a challenge for global health security. Biosecur Bioterror. 2014;12(5):263-73. https://doi.org/10.1089/bsp.2014.0032

24. Chen J, Chu S, Chungbaek Y, Khan M, Kuhlman C, Marathe A, et al. Effect of modelling slum populations on influenza spread in Delhi. BMJ Open. 2016; 6(9):e011699. https://doi.org/10.1136/bmjopen-2016-011699.

25. Adiga A, Chu S, Eubank S, Kuhlman CJ, Lewis B, Marathe A, et al. Disparities in spread and control of influenza in slums of Delhi: findings from an agent-based modelling study. BMJ Open. 2018;8(1):e017353. https://doi. org/10.1136/bmjopen-2017-017353.

26. Zargar A. India's poor hit hardest as coronavirus spreads and lockdown is extended. https://www.cbsnews.com/news/india-coronavirus-covid19-poorhit-hardest-lockdown-extended-narendra-modi-today-2020-04-14/. Accessed 13 May 2020.

27. Alahmad B, Kurdi H, Colonna K, Gasana J, Agnew J, Fox MA. COVID-19 stressors on migrant workers in Kuwait: cumulative risk considerations. BMJ Glob Health. 2020;5(7):e002995. https://doi.org/10.1136/bmjgh-2020-002995.

28. Koo JR, Cook AR, Park M, Sun Y, Sun H, Lim JT, et al. Interventions to mitigate early spread of SARS-CoV-2 in Singapore: a modelling study. Lancet Infect Dis. 2020;20(6):678-88. https://doi.org/10.1016/S1473-3 099(20)30162-6.

29. Cai W, Lai KKR. Packed With Migrant Workers, Dormitories Fuel Coronavirus in Singapore. The New York Times. 2020. https://www.nytimes.com/intera ctive/2020/04/28/world/asia/coronavirus-singapore-migrants.html. .

30. Pan A, Liu L, Wang C, Guo H, Hao X, Wang Q, et al. Association of Public Health Interventions with the epidemiology of the COVID-19 outbreak in Wuhan, China. JAMA. 2020.

31. Fong MW, Gao H, Wong JY, Xiao J, Shiu EYC, Ryu S, et al. Nonpharmaceutical measures for pandemic influenza in nonhealthcare settings-social distancing measures. Emerging Infect Dis. 2020;26(5):976-84. https://doi.org/10.3201/eid2605.190995.

32. Miyaki K, Sakurazawa H, Mikurube $H$, Nishizaka M, Ando H, Song $Y$, et al. An effective quarantine measure reduced the total incidence of influenza a H1N1 in the workplace: another way to control the H1N1 flu pandemic. J Occup Health. 2011;53(4):287-92. https://doi.org/10.153 9/joh.10-0024-FS.

33. van Gemert C, Hellard M, McBryde ES, Fielding J, Spelman T, Higgins N, et al. Intrahousehold transmission of pandemic (H1N1) 2009 virus, Victoria, Australia. Emerg Infect Dis. 2011;17(9):1599-607. https://doi.org/10.3201/eid1 709.101948.

34. Wei WE. Presymptomatic Transmission of SARS-CoV-2 - Singapore, January 23-March 16, 2020. MMWR Morb Mortal Wkly Rep. 2020;69. doi:https://doi. org/10.15585/mmwr.mm6914e1.

35. Bi Q, Wu Y, Mei S, Ye C, Zou X, Zhang Z, et al. Epidemiology and transmission of COVID-19 in 391 cases and 1286 of their close contacts in Shenzhen, China: a retrospective cohort study. Lancet Infect Dis. 2020;20(8): 911-9. https://doi.org/10.1016/S1473-3099(20)30287-5.

36. Li W, Zhang B, Lu J, Liu S, Chang Z, Cao P, et al. The characteristics of household transmission of COVID-19. Clin Infect Dis. 2020.

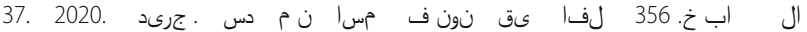
القبس ال ل ل ترون 11 . https://alqabas.com/article/5764616. Accessed 11 May 2020.

38. Alkhamis MA, Youha SA, Khajah MM, Haider NB, Alhardan S, Nabeel A, et al. Spatiotemporal dynamics of COVID-19 epidemic in the State of Kuwait. Int J Infect Dis. 2020;98:153-60. https://doi.org/10.1016/j.jiji.2020.06.078. 


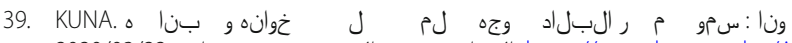

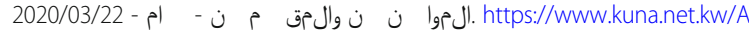
rticleDetails.aspx?id=2880748\&language=ar\#. Accessed 21 May 2020.

40. Nagraj. Kuwait to allow repatriation flights, offers amnesty for expats without valid residencies. Gulf Business. 2020. https://gulfbusiness.com/kuwa it-to-allow-repatriation-flights-offers-amnesty-for-expats-without-validresidencies/. Accessed 12 May 2020.

\section{Publisher's Note}

Springer Nature remains neutral with regard to jurisdictional claims in published maps and institutional affiliations.

Ready to submit your research? Choose BMC and benefit from:

- fast, convenient online submission

- thorough peer review by experienced researchers in your field

- rapid publication on acceptance

- support for research data, including large and complex data types

- gold Open Access which fosters wider collaboration and increased citations

- maximum visibility for your research: over $100 \mathrm{M}$ website views per year

At $\mathrm{BMC}$, research is always in progress. 